\title{
Interaction of TNT with Dopamine - A DFT Treatment
}

\section{Lemi Türker}

Department of Chemistry, Middle East Technical University, Üniversiteler, Eskişehir Yolu No: 1, 06800 Çankaya/Ankara, Turkey; e-mail: 1turker@gmail.com; lturker@metu.edu.tr

\begin{abstract}
2,4,6-trinitrotoluene, known as TNT is a widely used high explosive material. Its disastrous effects to health are reported but how it executes those effects biochemically has been scarcely studied. On the other hand, dopamine is an important endogenous catecholamine. The present study deals with interaction of TNT and dopamine within the restrictions of density functional theory at the level of B3LYP/6-31+G(d). Some structural, quantum chemical and spectral properties are obtained for TNT + dopamine composite. They may form two electronically stable $\pi$ - $\pi$ complex, TNT acting as $\pi$-acceptor and dopamine is the donor. Thermo chemical calculations indicate that formation of the complexes are unfavorable at the standard conditions but the endo-form of the complex is less unfavorable compared to the exo-form.
\end{abstract}

\section{Introduction}

2,4,6-Trinitrotoluene (or 2-methyl-1,3,5-trinitrobenzene) is a chemical compound with the formula $\mathrm{C}_{6} \mathrm{H}_{2}\left(\mathrm{NO}_{2}\right)_{3} \mathrm{CH}_{3}$. It is sometimes used as a reagent in chemical synthesis, but it is best known as an explosive material with convenient handling properties.

2,4,6-Trinitrotoluene is a yellow, odorless, solid manufactured compound that does not occur naturally in the environment. It is made by combining toluene with a mixture of nitric acid and sulfuric acid. 2,4,6-Trinitrotoluene is also known by other names such as sym-trinitrotoluene, TNT, and 1-methyl-2,4,6-trinitrobenzene. 2,4,6-Trinitrotoluene is

Received: June 6, 2019; Accepted: July 18, 2019

Keywords and phrases: 2,4,6-trinitrotoluene, TNT, dopamine, DFT, explosive.

Copyright (C) 2019 Lemi Türker. This is an open access article distributed under the Creative Commons Attribution License, which permits unrestricted use, distribution, and reproduction in any medium, provided the original work is properly cited. 
an explosive used in military shells, bombs, and grenades, in industrial uses, and in underwater blasting.

2,4,6-Trinitrotoluene enters the environment in waste waters and solid wastes resulting from the manufacture of the compound, the processing and destruction of bombs and grenades, and the recycling of explosives. The compound moves in surface water and through soils to groundwater. In surface water, 2,4,6-trinitrotoluene is rapidly broken down into other chemical compounds by sunlight. Microorganisms in water and sediment break down the compound more slowly. Small amounts of 2,4,6-trinitrotoluene can accumulate in fish and plants $[1,2]$.

Most exposure would result from drinking contaminated water, breathing contaminated 2,4,6-trinitrotoluene air, or eating contaminated foods such as fruits and vegetables. Workers exposure to 2,4,6-trinitrotoluene is possible as a result of its use in the production of bombs and grenades. Most workplace exposure results from breathing in 2,4,6-trinitrotoluene dust or vapor and contact with dust on the skin. 2,4,6Trinitrotoluene rapidly and completely enters your body when you breathe in air or drink water that is contaminated with this chemical $[3,4]$.

There are tests to determine if you have been exposed to 2,4,6-trinitrotoluene. These tests measure 2,4,6-trinitrotoluene or its breakdown products in blood and urine and have been used to test exposed workers [5]. Detection of the breakdown products in urine is a clear indication that person has been exposed. The complex and expensive equipment needed to perform these tests is generally available only at specialized laboratories [6]. Another simpler, but less specific, test of 2,4,6-trinitrotoluene exposure is a change in the color of urine to amber or deep red [5]. This change results from the presence of breakdown products and may indicate that person has been exposed to 2,4,6trinitrotoluene. Amino compounds for binding 2,4,6-trinitrotoluene in water has been used [7]. None of these tests can predict whether a person exposed to 2,4,6trinitrotoluene will experience any health effects related to the exposure.

It is well-known that TNT is toxic and carcinogenic and causes anemia, abnormal liver function, and cataracts [8-11]. Toxicogenomic analysis provides insights into molecular mechanisms of the sublethal toxicity of 2,4,6-trinitrotoluene in certain species [12].

Dopamine is one of the important endogenous catecholamines which exerts widespread effects both in neuronal (as a neurotransmitter) and non-neuronal tissues 
(as an autocrine or paracrine agent). Dopamine binds to specific membrane receptors

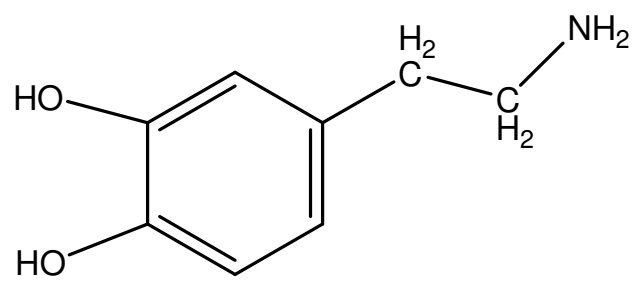

\section{Dopamine}

presented by neurons in the central nervous system and it plays the key role in the control of locomotion, learning, working memory, cognition, and emotion [13-15]. The brain dopamine system is involved in various neurological and psychiatric disturbances such as Parkinson's disease, schizophrenia, and amphetamine and cocaine addiction [16]. Thus, this system is the major target of powerful drugs applied in the treatment of neuropsychiatric diseases. Physiological functions of the brain dopamine system are well recognized. However, dopamine biosynthesis does not only occur in neurons, but also in peripheral tissues. Dopamine receptors have been described in the kidney, pancreas, lungs, and in numerous blood vessels outside the central nervous system. Renal dopamine is now recognized as an important regulator of sodium extraction and electrolyte balance, while defective renal dopamine production and/or dopamine receptor function may contribute to the development of various forms of human and animal hypertension [13-15].

In the present study, a $\pi-\pi$ complex is considered between TNT and dopamine within the restrictions of density functional theory.

\section{Computational Method}

In the present treatise, the geometry optimizations of the structures under consideration leading to energy minima were achieved by performing MM2 molecular mechanics calculations (equilibrium conformer) followed by PM3 [17, 18], HF and then closed shell density functional theory (DFT) [19] calculations using B3LYP hybrid exchange-correlation potential [20] employing 6-31+G(d) basis set. The exchange term of B3LYP consists of hybrid Hartree-Fock and local spin density (LSD) exchange functions with Becke's gradient correlation to LSD exchange [21]. The correlation term of B3LYP consists of the Vosko, Wilk, Nusair (VWN3) local correlation functional [22] 
and Lee, Yang, Parr (LYP) correlation correction functional [23]. The BLYP method gives a better improvement over the SCF-HF results. The optimizations in the present study have been obtained by the use of SPARTAN 06 program [24].

\section{Results and Discussion}

TNT having three nitro groups (capable of exerting strong mesomericaly electron attracting power) possesses an electron deficient aromatic kernel. Thus, it has powerful electron acceptor character against electron donor structures. In that sense, dopamine having catechol kernel may perform the role of a donor. Note that it has two $\mathrm{OH}$ groups linked to the aromatic ring, thus mesomerically enrich the structure of the ring.

The $\pi-\pi$ complex formed between TNT and dopamine may be in the endo- and exoforms. Figure 1 shows the optimized structures of these two complexes which are slightly slipped-stacked orientation [25]. In each case the positive end of the dipole moment vector is nearby the ethylamine moiety of dopamine. The calculated lengths of the presumably existing $\pi-\pi$ bonds are $4.230 \AA$ and $4.169 \AA$, respectively for complex-I and II.
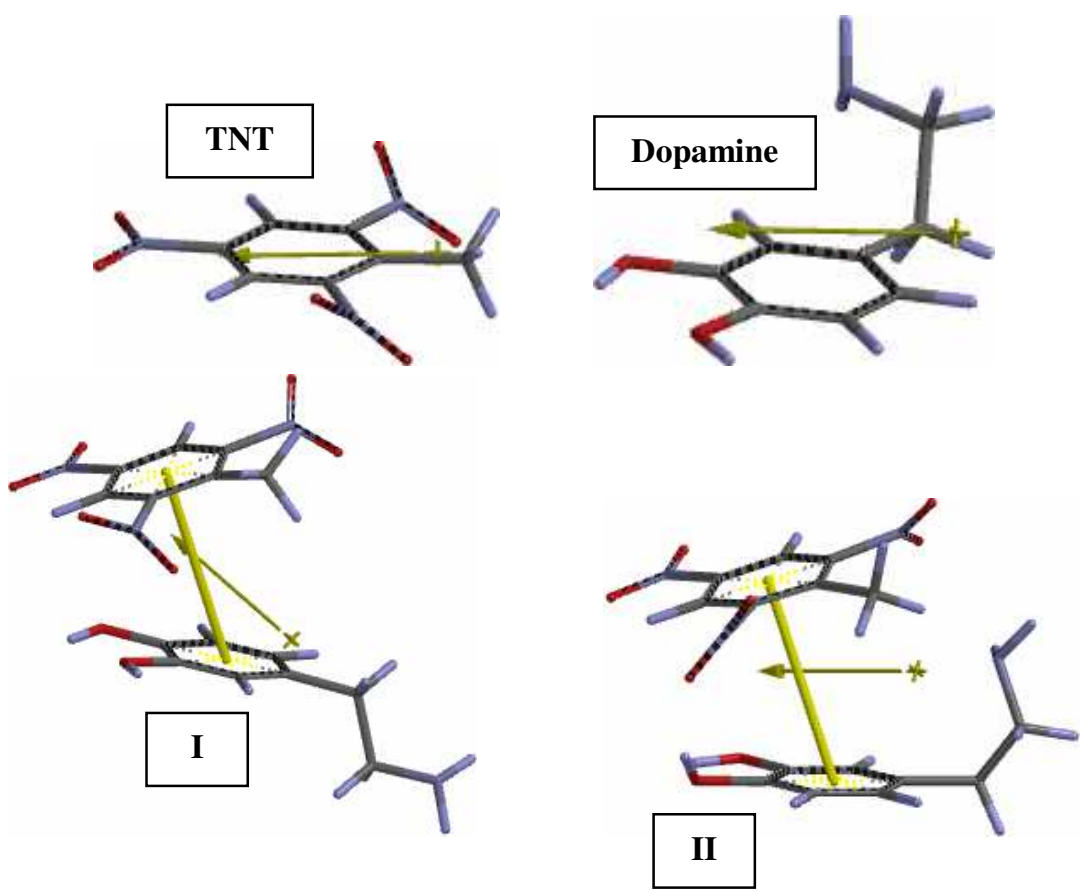

Figure 1. Optimized structure of the components and complexes between them. 
Figure 2 shows the calculated bond lengths of the complexes. Complex-I and II are the exo- and endo-isomers, respectively.
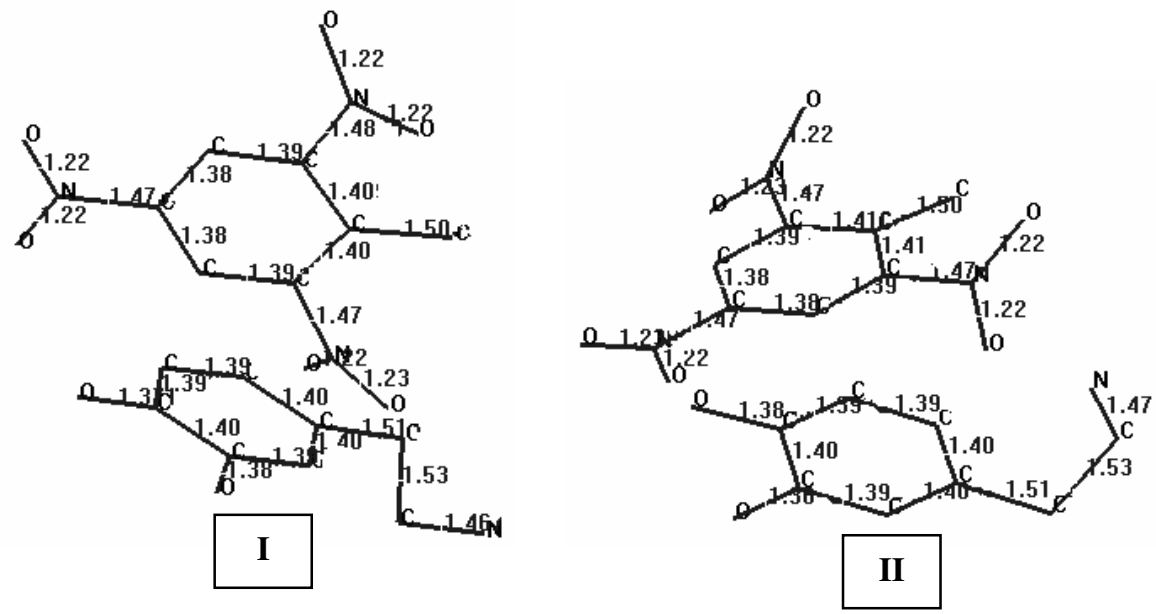

Figure 2. Calculated bond lengths ( $⿱$ ) of the complexes (Hydrogens not shown).

Figure 3 shows the ESP charges on the atoms of the complexes. Note that ESP charges are obtained by the program based on a numerical method that generates charges that reproduce the electrostatic field from the entire wave function [24].
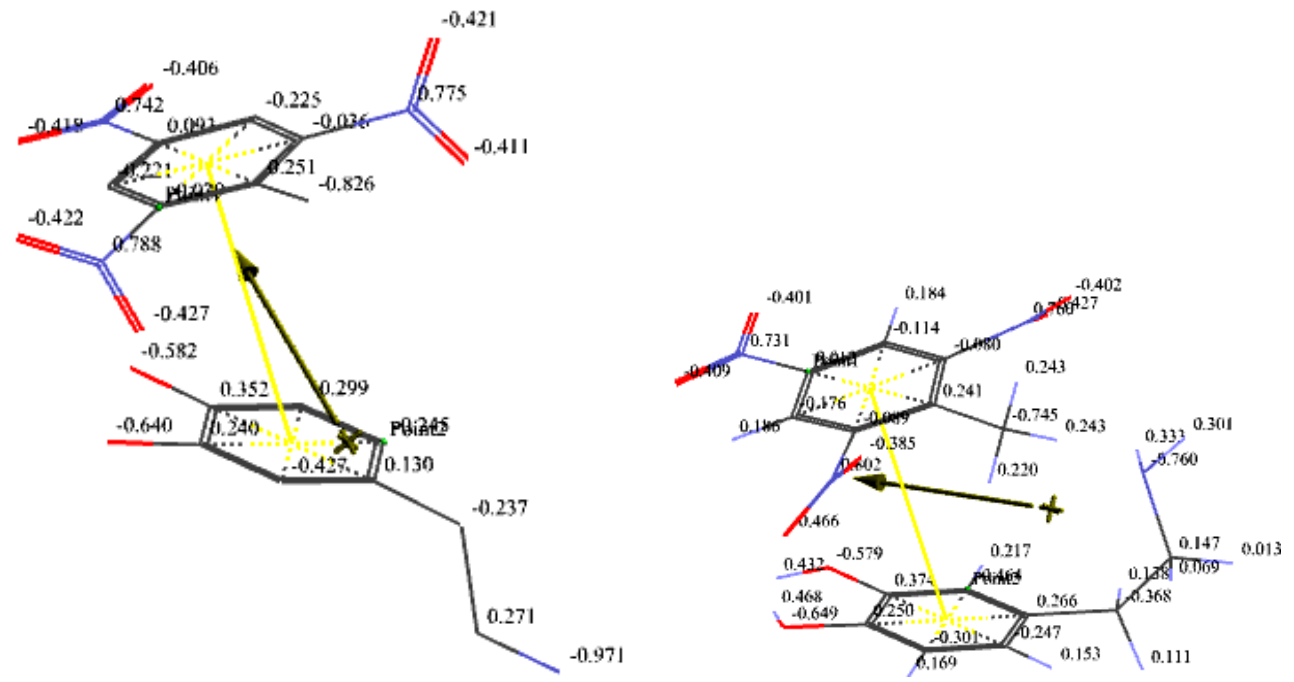

Figure 3. Electrostatic charges on the atoms (ESP charges, hydrogens not shown).

Table 1 tabulates some energies of the complexes considered. $\mathrm{E}$ and $\mathrm{E}_{\mathrm{c}}$ stand for the total electronic energy and its corrected form, respectively. The corrected energy 
includes the zero point vibrational energy (ZPE) contribution. The data in the table indicate that complex-II is more stable than complex-I. The $\pi-\pi$ bonding in the complexes are $4.230 \AA$ and $4.169 \AA$, respectively for complex-I and II.

Table 1. Some energies of the complexes.

\begin{tabular}{cccc}
\hline Structure & $\mathbf{E}$ & $\mathbf{Z P E}$ & $\mathbf{E}_{\mathbf{c}}$ \\
\hline I & -3680348.80 & 837.82 & -3679510.98 \\
II & -3680359.76 & 841.04 & -3679518.72 \\
\hline
\end{tabular}

Energies in $\mathrm{kJ} / \mathrm{mol}$.

Table 2 shows some thermo chemical properties of the species considered. Note that in each case $\Delta_{\text {reacn }}$ values for the complex formation is unfavorable at the standard conditions.

Table 2. Some thermo chemical properties of the species considered.

\begin{tabular}{llll}
\hline & $\mathbf{H}^{\mathbf{0}}(\mathrm{kJ} / \mathrm{mol})$. & $\mathbf{S}^{\mathbf{o}}(\mathrm{J} / \mathrm{mol})$. & $\mathbf{G}^{\mathbf{o}}(\mathrm{kJ} / \mathrm{mol})$. \\
\hline TNT & -2323419.582 & 444.32 & -2323552.056 \\
DOPA & -1356045.126 & 399.49 & -1356164.236 \\
$\mathbf{I}$ & -3679486.658 & 611.86 & -3679669.106 \\
$\mathbf{I I}$ & -3679495.269 & 604.78 & -3679675.591 \\
$\boldsymbol{\Delta}_{\text {reac }}(\mathbf{I})$ & -21.95 & -231.95 & 47.186 \\
$\boldsymbol{\Delta}_{\text {reac }}(\mathbf{I I})$ & -30.561 & -239.03 & 40.701 \\
\hline
\end{tabular}

Figure 4 includes IR spectra of the components and the complexes. Dopamine and complex-I have sharp peaks at $3500-4000 \mathrm{~cm}^{-1}$ which are $\mathrm{NH}_{2}$ and $\mathrm{OH}$ bands. Instead of those peaks, in complex-II only a single peak appears in that region. 

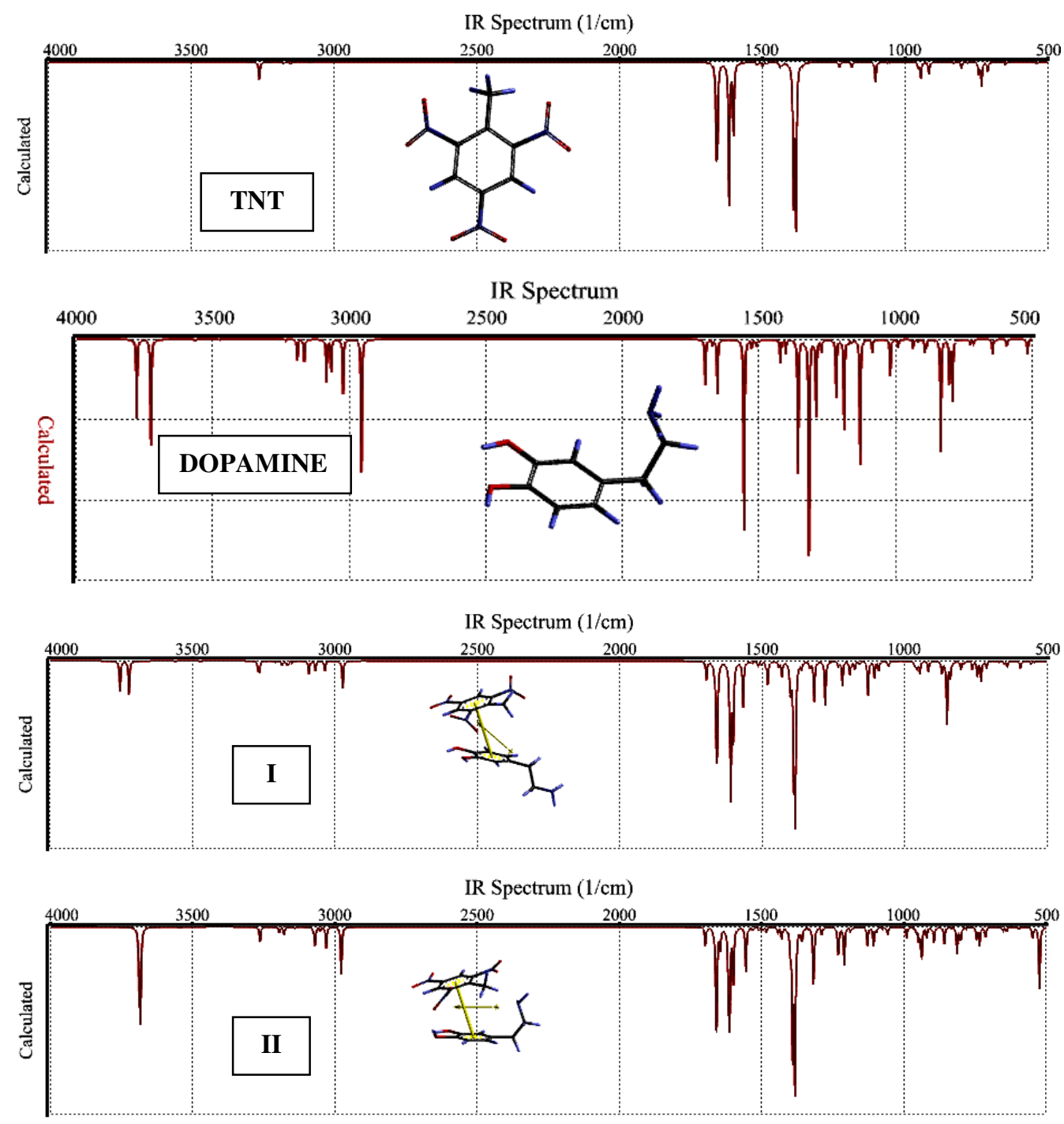

Figure 4. IR spectrum of the components and the complexes.

Figure 5 depicts the UV-VIS spectrums (time-dependent DFT) of the components and the complexes. Although, both of the components absorb in the UV region below $400 \mathrm{~nm}$, the complexes absorb in the visible region. The pattern of visible region for the complexes is highly different from each other. In general, complex-II spectrum exhibits bathochromic effect relative to the spectrum of complex-I. Such a situation usually happens when a much better conjugations happen among the chromaphoric group present in the structure. Possibly the nitro groups of TNT component are responsible for such a 

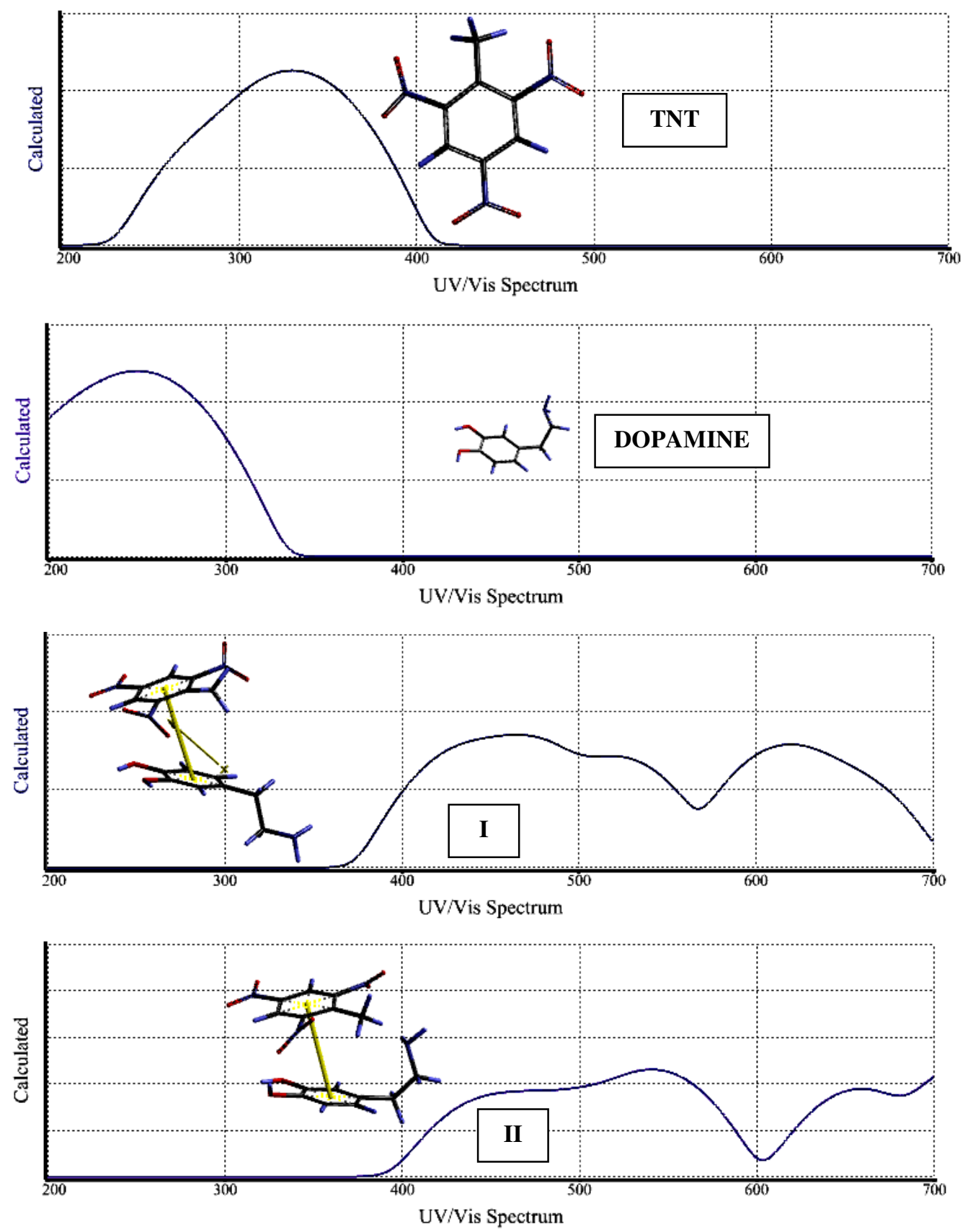

Figure 5. UV-VIS spectrum of the components and the complexes. 
difference between the complexes and the ethylamino group should have some influence on the orientation of $\mathrm{NO}_{2}$ substituents.

Figure 6 shows some of the molecular orbital energy levels of the components and their complexes. TNT is characterized with a rather low HOMO energy level as compared to dopamine. On the contrary, the LUMO energy level of dopamine is high. As
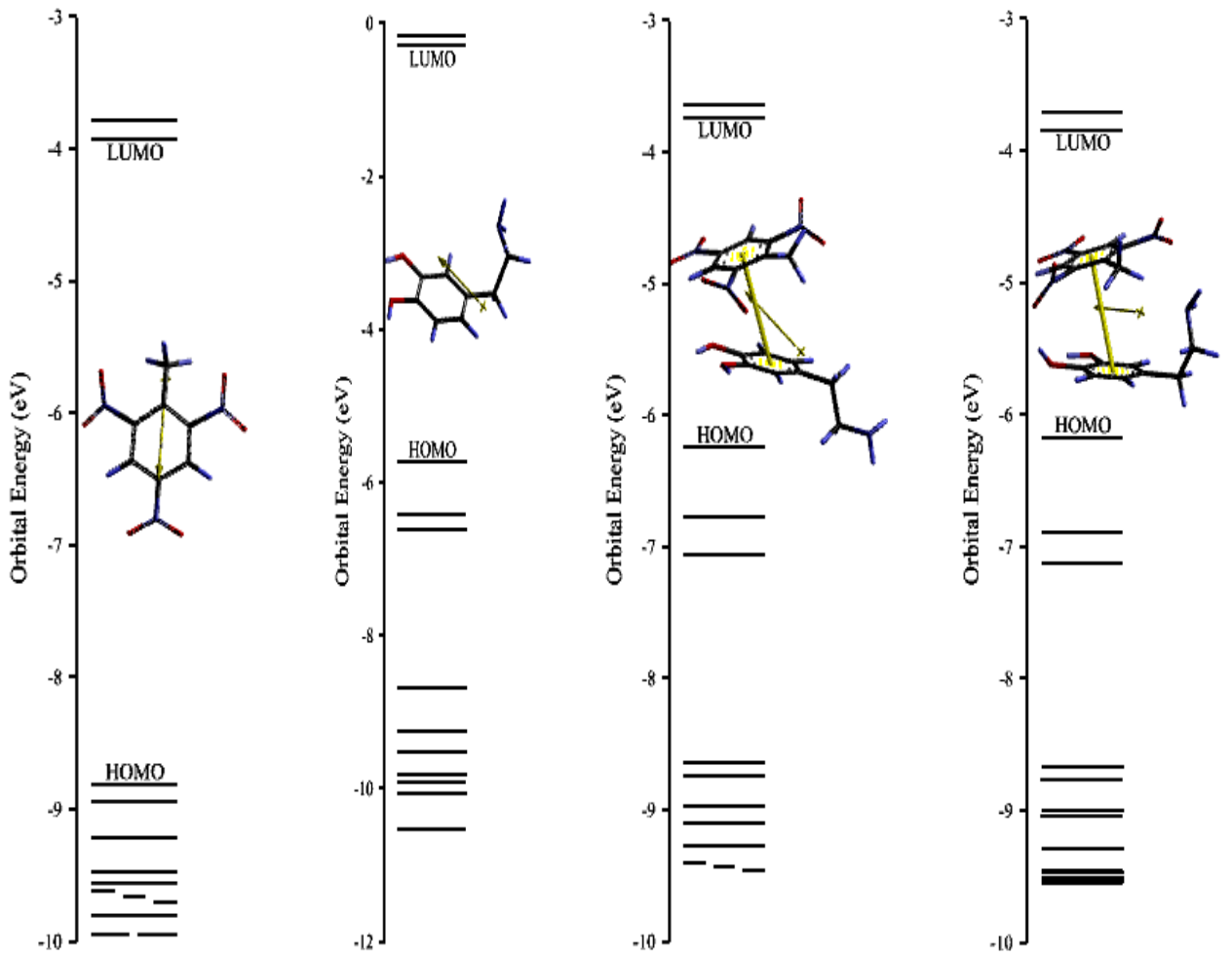

Figure 6. Some of the orbital energies of the components and the complexes.

for the complexes, complex-II has comparatively higher HOMO but lower LUMO energy levels (see Table 3). The NEXT LUMO level of complex-I is closer to the HOMO level, in contrast to the same case in complex-II. Also note that the complex formation affects the spacings of some inner lying molecular orbitals of complex-II as compared to complex-I. Table 3 also shows the interfrontier molecular orbital energy gap values $(\Delta \varepsilon)$. The order of $\Delta \varepsilon$ values is Dopamine $>$ TNT $>$ I $>$ II. 
Table 3. The HOMO, LUMO energies and interfrontier molecular orbital energy gaps.

\begin{tabular}{lccc}
\hline Structure & HOMO & LUMO & $\Delta \varepsilon$ \\
\hline TNT & -849.87 & -379.27 & 470.6 \\
Dopamine & -552.85 & -28.82 & 524.03 \\
I & -602.05 & -360.44 & 241.61 \\
II & -595.52 & -370.73 & 224.79 \\
\hline
\end{tabular}

Energies in $\mathrm{kJ} / \mathrm{mol}$.

Figure 7 shows the HOMO and LUMO patterns of the systems considered. As seen

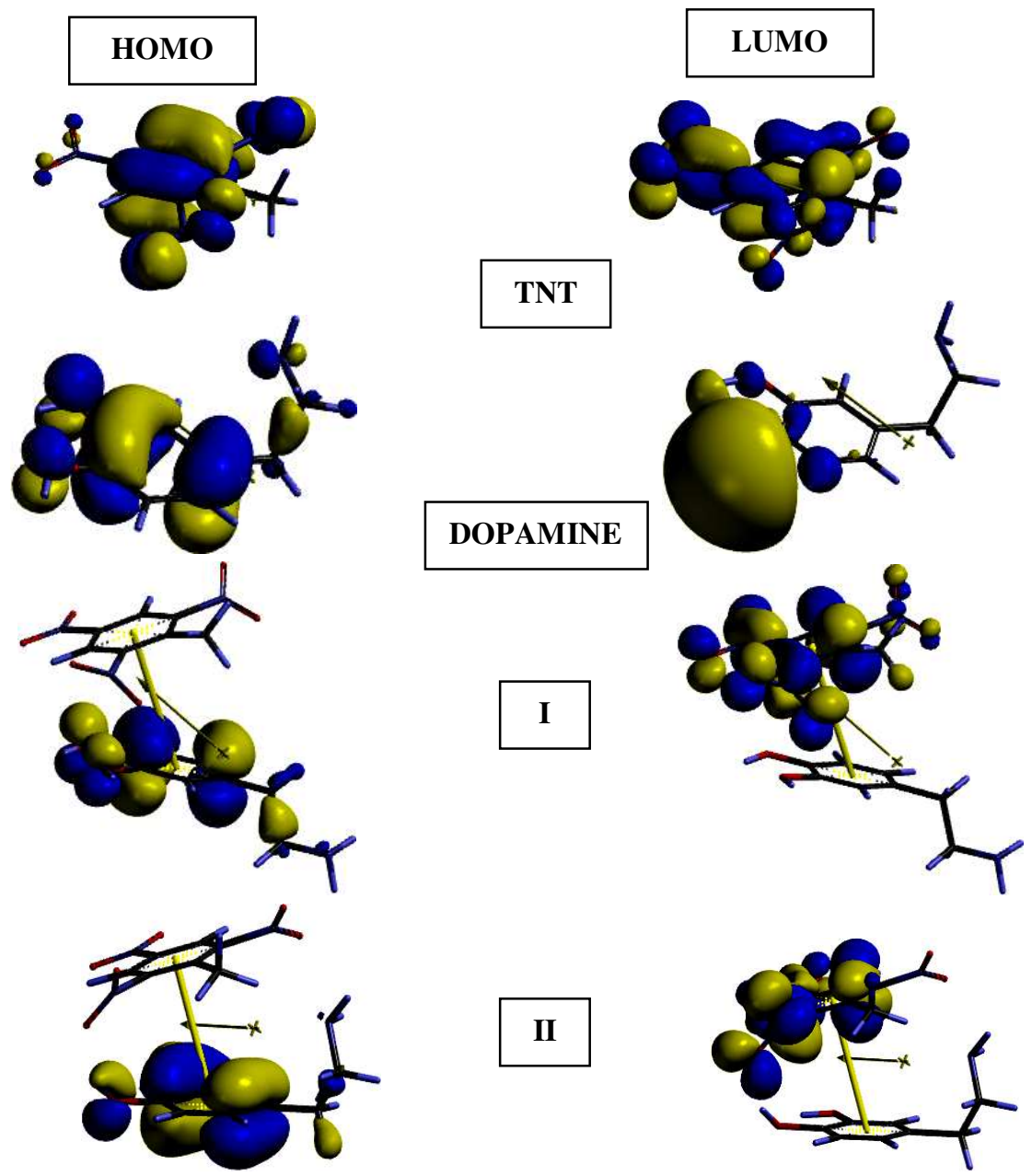

Figure 7. The HOMO and LUMO patterns of the components and the complexes. 
from the figure, TNT moiety is the supplier of the LUMO of the complexes. Whereas the HOMOs are supplied by dopamine. However, the HOMO and LUMO patterns of the complexes are highly different from the respective patterns of the components.

Figure 8 shows the electrostatic potential maps of the complexes. The high electronegative potential on the amino group of dopamine in complex-I is no longer exists on the same site in complex-II. Note that complex-II is electronically more stable than complex-I. Also note that the interaction energy between two interacting species possesses contributions from columbic forces (attractive and/or repulsive) and orbital interactions [26]. Because of all these intricate factors, (as seen in Table 2) $\Delta_{\text {reac }}$ value of the formation of complex-II is less unfavorable as compared to complex-I.
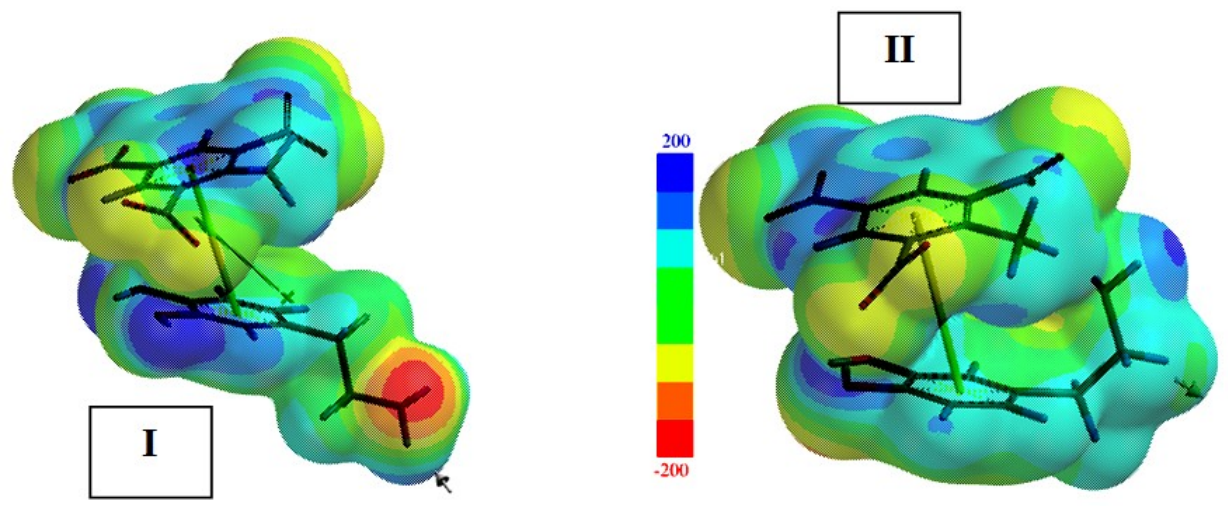

Figure 8. Electrostatic potential maps of the complexes.

\section{Conclusion}

Within the restrictions of density functional theory at the level of B3LYP/6-31+G(d), the interaction of TNT and dopamine has been considered. The results of some structural, quantum chemical, thermo chemical and spectral properties of TNT + dopamine composite reveal that they may form two electronically stable $\pi-\pi$ complex, in which TNT acting as $\pi$-acceptor and dopamine is the donor. The thermo chemical calculations indicate that the complexes are unfavorable at the standard conditions but the endo-form of the complex is more stable and less unfavorable compared to the exoform. The present calculations have been carried out in vacuum conditions. Solvent effects would be worth studying for understanding the effect of TNT on dopamine metabolism in living organisms. 


\section{References}

[1] D. P. Agarwal and H. W. Goedde, Pharmacogenetics and ecogenetics, Experientia (Basel) 42(10) (1986), 1148-1154. https://doi.org/10.1007/BF01941289

[2] P. Leffler, E. Brännäs, D. Ragnvaldsson, H. Wingfors and R. Berglind, Toxicity and accumulation of trinitrotoluene (TNT) and its metabolites in atlantic salmon alevins exposed to an industrially polluted water, J. Toxicol. Environ. Health A 77 (2014), 11831191. https://doi.org/10.1080/15287394.2014.920756

[3] J. V. Dilley, C. A. Tyson, R. J. Spanggord, D. P. Sasmore, G. W. Newell and J. C. Dacre, Short-term oral toxicity of 2,4,6-trinitrotoluene in mice, rats, and dogs, J. Toxicol. Environ. Health 9(4) (1982), 565-585. https://doi.org/10.1080/15287398209530188

[4] A. Zitting, G. Szumańska, J. Nickels and H. Savolainen, Acute toxic effects of trinitrotoluene on rat brain, liver and kidney: role of radical production, Arch. Toxicol. 51 (1982), 53-64. https://doi.org/10.1007/BF00279321

[5] J. Almog, S. Kraus and A. Basch, Determination of T.N.T. metabolites in urine, Arch. Toxicol. [Suppl.] 6 (1983), 351-353. https://doi.org/10.1007/978-3-642-69083-9_64

[6] K. Bratin, P. T. Kissinger, R. C. Briner and C. S. Bruntlett, Determination of nitro aromatic, nitramine and nitrate ester explosive compounds in explosive mixtures and gunshot residue by liquid chromatography and reductive electrochemical detection, Anal. Chim. Acta 130(2) (1981), 295-311. https://doi.org/10.1016/S0003-2670(01)93007-7

[7] F. Fant, A. De Sloovere, K. Matthijsen, C. Marla, S. El Fantroussi, W. Verstraete, K. Ayoub, E. D. van Hullebusch, M. Cassir and A. Bermond, The use of amino compounds for binding 2,4,6-trinitrotoluene in water: Application of advanced oxidation processes for TNT removal: A review, Environ. Poll. 111 (2001), 503-507.

https://doi.org/10.1016/S0269-7491(00)00077-4

[8] D. Garfinkel, Y. Sidi and M. Steier, Liver cirrhosis and hepatocellular carcinoma after prolonged exposure to TNT: Causal relationship or mere coincidence?, Med. Intern. 26(4) (1988), 287-290.

[9] H. Harkonen, M. Karki, A. Lahti and H. Savolainen, Early equatorial cataracts in workers exposed to trinitrotoluene, Am. J. Ophthalmol. 95(6) (1983), 807-810. https://doi.org/10.1016/0002-9394(83)90070-3

[10] S. Homma-Takeda, Y. Hiraku, Y. Ohkuma, S. Oikawa, M. Murata, K. Ogawa, T. Iwamuro, S. Li, G. F. Sun, Y. Kumagai, N. Shimojo and S. Kawanishi, 2,4,6Trinitrotoluene-induced reproductive toxicity via oxidative DNA damage by its metabolite, Free Radical Res. 36 (2002), 555-566.

https://doi.org/10.1080/10715760290025933 
[11] S. Letzel, T. Göen, M. Bader, J. Angerer and T. Kraus, Exposure to nitroaromatic explosives and health effects during disposal of military waste, Occup. Environ. Med. 60 (2003), 483-488. https://doi.org/10.1136/oem.60.7.483

[12] P. Gong, X. Guan, L. S. Inouye, M. Pirooznia, K. J. Indest, R. S. Athow, Y. Deng and E. J. Perkins, Toxicogenomic analysis provides new insights into molecular mechanisms of the sublethal toxicity of 2,4,6-trinitrotoluene in Eisenia fetida, Environ. Sci. Technol. 41 (2007), 8195-8202. https://doi.org/10.1021/es0716352

[13] J. Drozak and J. Bryła, Dopamine: not just a neurotransmitter [in Polish], Postepy. Hig. Med. Dosw. (Online) 59 (2005), 405-420.

[14] J. D. Jentsch, R. H. Roth and J. R. Taylor, Role for dopamine in the behavioral functions of the prefrontal corticostriatal system: implications for mental disorders and psychotropic drug action, Prog. Brain Res. 126 (2000), 433-453.

https://doi.org/10.1016/S0079-6123(00)26028-7

[15] M. T. Tse, A. Cantor and S. B. Floresco, Repeated amphetamine exposure disrupts dopaminergic modulation of amygdala-prefrontal circuitry and cognitive/emotional functioning, J. Neurosci. 31(31) (2011), 11282-11294.

https://doi.org/10.1523/JNEUROSCI.1810-11.2011

[16] J. A. Borovac, Side effects of a dopamine agonist therapy for Parkinson's disease: a minireview of clinical pharmacology, Yale J. Biol. Med. 89(1) (2016), 37-47.

[17] J. J. P. Stewart, Optimization of parameters for semiempirical methods II. Applications, J. Comput. Chem. 10 (1989), 221-264. https://doi.org/10.1002/jcc.540100209

[18] J. J. P. Stewart, Optimization of parameters for semiempirical methods I. Method, $J$. Comput. Chem. 10 (1989), 209-220. https://doi.org/10.1002/jcc.540100208

[19] W. Kohn and L. J. Sham, Self-consistent equations including exchange and correlation Effects, Phys. Rev. A 140 (1965), 1133-1138. https://doi.org/10.1103/PhysRev.140.A1133

[20] R. G. Parr and W. Yang, Density Functional Theory of Atoms and Molecules, London: Oxford University Press, 1989.

[21] A. D. Becke, Density-functional exchange-energy approximation with correct asymptotic behavior, Phys. Rev. A 38 (1988), 3098-3100. https://doi.org/10.1103/PhysRevA.38.3098

[22] S. H. Vosko, L. Wilk and M. Nusair, Accurate spin-dependent electron liquid correlation energies for local spin density calculations: a critical analysis, Can. J. Phys. 58 (1980), 1200-1211. https://doi.org/10.1139/p80-159 
[23] C. Lee, W. Yang and R. G. Parr, Development of the Colle-Salvetti correlation-energy formula into a functional of the electron density, Phys. Rev. B 37 (1988), 785-789. https://doi.org/10.1103/PhysRevB.37.785

[24] Spartan 06 Program, Wavefunction Inc., Irvine, CA 92612 USA, 2006.

[25] E. V. Anslyn and D. A. Dougherty, Modern Physical Organic Chemistry, Sausalito, California, USA: University Science Books, p. 184, 186, 2006.

[26] I. Fleming, Frontier Orbitals and Organic Chemical Reactions, NY: Wiley, 1976. 